\title{
The Effectiveness of Group Psychotherapy Based on Acceptance and Commitment on Increasing of Mental Health and the Quality of Women's Life with Breast Cancer
}

\author{
Ahmad Esmali ${ }^{*}$ and Masoomeh Alizadeh ${ }^{2}$ \\ ${ }^{1}$ Department of Psychology, School of Litrature, Maragheh University, Maragheh, Iran. \\ ${ }^{2}$ Master Degree of Clinical Psychology, Urmia Branch, Islamic Azad University, Urmia, Iran.
}

DOI: http://dx.doi.org/10.13005/bbra/1898

(Received: 16 September 2015; accepted: 30 October 2015)

The target of current research was to determine the effectiveness of group psychotherapy based on acceptance and commitment on increasing of mental health and the quality of patients' life with breast cancer, For this purpose, in a semi trial research 30 persons of women with breast cancer in Omid hospital of Urmia city were selected with available sampling method and they were randomly divided into two trial (15 persons) and control (15 persons) groups. Test group received an interference based on acceptance and commitment in 8 sessions (each session 90 minutes), but no interference was accomplished on control group. Both groups were tested in two pre-test and post-test stages by questionnaire of Quality Of Lifefor patients with breast cancer (QOL_BR23) and Goldberg mental Health Questionnaire of Goldberg (GHQ). The results of covariance analysis showed that therapeutic plan could improve all aspects of mental health of test group subjects and two aspects of social health and physical health of life quality but it couldn't influence on conditions of subjects in two aspects of psychological health and environmental health of interference. Therefore we can express that group psychotherapy based on acceptance and commitment can be effective on promotion of mental health and quality of patients' life with breast cancer.

Key words: Acceptance and commitment therapy, breast cancer, mental health, quality of life.

Cancer is a group of diseases characterized by uncontrolled growth and spread of unnatural cells (American Cancer Society, 2015). Breast cancer is the most common cancers in women all around the world which has the highest mortality rate among female patients affected by cancer. The outbreak rate of breast cancer differs from one place to another place of the world (Jemal, bray, Center, Ferlay, Ward \&Foman, 2011; Costanza, Chen, 2011; Yankaskas, 2005) and about one-fifth of all mortality in women is in the age of 40-50 (Yen, Ko, Yen, Yang et al, 2006). Also in Iran,

\footnotetext{
* To whom all correspondence should be addressed.
}

breast cancer includes 22.26 percent of women's cancer and it is the most common cancer among Iranian women (Esmaili, Abed Saeedi and AlaviMajd, 2010). The researches have already known potential risk factors like inheritance, Hormonal and fertility factors, environmental factors like life style and especially mental factors interfering on outbreak of breast cancer (America Cancer Society, 2015; Bamett, Shah, Redman, Easton, Ponder, Pharoah, 2008; DemarkWahnefried, Aziz, Rouland, Pinto, 2005).

Women with breast cancer are cured by therapies like surgery, radiotherapy, chemotherapy, hormonotherapy, immunotherapy and target therapy ( the drugs which are especially known interfering in growth of cancerous cells, America 
Cancer Society, 2015). The results of researches indicate the prominent consequences of breast cancer; like physical problems (pain and fatigue), psychological problems (anxiety and depression) and other psychological-social problems in affected persons; this leads to decrease the quality of life especially with regard to younger women (Spiegel \&Riba, 2015; So, Marsh, Ling, Leung et al, 2009).

According to the definition of World Health Organization, the quality of life is the persons perception of their condition in terms of culture, value system in which we live, targets, expectations, standards and their priorities; this concept is completely subjective, it is not observable by others and it is based on persons perception from different aspects of life (World Health Organization, 1996).

The studies have shown that the quality of women's life with breast cancer is significantly lower than non-patient young women (Avis, Crawford \& Manuel, 2005; Reich, Lesur, PerdizetChevallier, 2008; Reyes-Gibby, Anderson, Morrow, Shete\&hassan, 2012).

Also many underlying and side factors are able to influence on condition of mental health and life of these patients (Lehto, ojanen, Dyba, Aromaa, \&Kellokumpu-Lehtinen, 2006).

According to the report of World Health Organization, mental health includes subjective well-being, perceived self -efficiency, independency, intergenerational dependence and self-actualization of person' s intellectual and emotional potential among others (World Health organization, 2001).

Patients with breast cancer show high rate of anxiety (Drageset\& Lindstrom, 2003) and higher outbreak of depression from slight to middle with low quality of life (Reich, Lesur, Perdizet, Chevallier, 2008), although these findings are in contrast to the results of t-test in Colby \&Shifren research (2013) that have shown women with breast cancer have had less score in pessimism, more positive mental health and they have presented good report in life quality domain. The studies show that acceptance and Commitment therapy is an effective method in decreasing anxiety and depression in women with breast cancer (Mohabbatbahar, MalekiRizi, Akbari and Moradijou, 2015; Mojtabaee, Gholamhosseini, 2014). Also acceptance and commitment therapy anticipates the changes in psychological flexibility, changes in quality of life, distress, moods (Feros, Lane, Ciarrochi\&Blackdege, 2013).

Acceptance and commitment Therapy is a proces s-oriented approach which is known as one of the third-wave Psychotherapy (hayes, Luom, Bond, Masuda \& Lillis, 2006). Acceptance and commitment therapy is a form of analysis of clinical behavior which is used in psychotherapy (Plumb, Stewart, Dahl \& Lundgren, 2009) and it is a therapeutic method that teaches mindfulness (concentrating on a especial method: target, present moment, unfair judgement) and acceptance (openness, willingness to maintain the contact) and skills for responding to uncontrolled experiences and consequently commitment to personal values. It is a therapy for decreasing the worries with eliminating unwanted thoughts, emotions and sensations and much worries with psychological flexibility (ability for changing the behavior depending on this issue that how can this behavior be suitable and perceived for patient s life in long-term?) (Aayes, Strosahl\& Wilson, 2012). Acceptance and commitment Therapy struggles for reaching to increase the mental health of patients with breast cancer through acceptance, concentrating on present moments and commitment to value of life (Angiola\& Bowen, 2013). According to this, the researcher is looking for this issue that whether Acceptance and Commitment Therapy is effective on increasing the mental health and quality of patient life with breast cancer or not?

\section{Methodology}

Current research is a semi-trial kind according to pre-test and post-test design with control group. The population of this research included the women with breast cancer of Omid hospital in Urmia city in autumn 2014-2015. 30 persons were selected from this population by available sampling method and they were randomly divided into two trial (15 persons)and control (15 persons) groups. Having motivation for taking part in the program and persons, satisfaction and necessary cooperation with researcher at the time of primary interview were taken. The standards of entering to the test stage consist of: having the age of 30 to 50 , all persons should experience chemotherapy and shouldn't have any other 
physical disease and the standards of exiting from group psychotherapy sessions consisted of having absence more than 2 sessions and lack of physical ability due to growing process of disease. Before interference and after the end of it, those subjects were tested by questionnaire of Quality Of Life for patients with breast cancer (QOL_BR23) and Goldberg mental Health Questionnaire.
The data collection tools in this research consisted of:

A-questionnaire of Quality Of Life for patients with breast cancer (QOL_BR23):

This questionnaire is used to evaluate the quality of person's life in two recent weeks. This questionnaire includes 26 questions in five-degree Likret scale in the frame of 4 domains of physical

Table 1. the summary of therapy sessions

Explanation of sessions with homework

First session: establishment of contact therapy (by using of the metaphor of two mounts)- familiarizing the persons with research case and the rules of group, explaining the breast cancer, symptoms, medicinal and non-medicinal therapies, evaluating the willingness rate of person for changing, evaluating the person's expectations from therapy.Second session: a review on talks of first session, the main target of this session is to create creative distress namely the patients finally come to the view that each kind of struggle that they have already done, was useless and from this moment instead of self-blame they should apply new methods to change the condition by using of allegory (human in well, drawstring match with monster, hungry tiger), we teach the patient that avoiding or another control method just strengthens the importance and role of what he/she avoids from it. Getting feedback and presenting homework.Third session: the main target in this session is to teach and explain this case that control itself is problem not solution. Explaining this case that interior incidents can't be controlled like exterior ones and teaching the control detection of personal incidents like thoughts, memories and detecting the inefficient control solutions and finding out their uselessness, accepting painful personal incidents without conflict with them and lack of controlling them by using of allegory (polygraph and falling in love), getting the feedback and presenting homework.Fourth session: the main target in this session is to teach the willingness of better replacement for control. Teaching the acceptance of all interior incidents and explaining about avoiding from painful experiences and awareness of avoidance consequences by using of metaphors like uninvited guest and caught the cat's foot in skein. Changing the language concepts by using of allegory (lion, milk, tap), teaching relaxation, getting the feedback and presenting the homework.Fifth session: stating the concept of fault cognitive by using of allegories of bus and marching of the soldiers that the final target is to create a distance between patients and thoughts, sensations, memories and his/her physical sensations, finally the patient sees the interior reactions in an observer level and it doesn't combine with them, example: I recognized that I am getting anxious.Sixth session: explaining the concepts of role and underlie, observing himself/herself as a context and establishment of contact with himself/herself by using of chess allegory and metaphor of house with furniture, awareness of different sensory perceptions and separation from senses which are the component of subjective content. In these experiences, participants are taught to concentrate on their activities (like breathing, walking) and be aware of their conditions in each moment and be observed without justification when emotions, sensations and cognitions are processed. When participants perceive that mind has been divagated inside the thoughts, memories or fantasies if possible and regardless to content and their nature they incline their attention to the present time. Therefore participants are taught to pay attention to their thoughts and sensations but not to stick to their content; getting the feedback and presenting the homework.Seventh session: explaining the concept of values and stating the difference between values, targets and needs, explaining the values of patients, creating the motivation to change and enable them for better life and help them to concentrate on living with effective method, in fact in this session we distinguish between value as a sense and value as an action, performing the experiences to identify the values of patients like their funeral practice and presenting the grading form of values evaluation, getting the feedback and presenting the homework.Eight session: teaching the commitment to the action, identifying the behavioral designs according to the values and creating the commitment for doing them namely the patients distinguish between willingness and wanting, this is done an a trial basis by using of "beggar at the door" allegory and finally the patient will conclude that avoiding from willingness doesn't increase the mind relaxation, reviewing the homework and summarizing the sessions with patients, performing the post-test. 
health, psychological health, social and environmental health. In reported results by manufacturer group of life quality scale of World Health Organization which have been done in 15 international centers of this organization, Koroonbakh Alfa Coefficient has been reported between $\% 73$ to $\% 89$ for quadruple subscales and whole scale (Skevington, Lotfy, \&OConnel, 2004).

Table 2. Descriptive components of "mental health and quality of life" scores in pre-test and post-test

\begin{tabular}{|c|c|c|c|c|c|}
\hline \multirow[t]{2}{*}{ Variables } & \multirow[t]{2}{*}{ Group } & \multirow{2}{*}{$\begin{array}{l}\text { Pre-test } \\
\text { Average }\end{array}$} & \multicolumn{3}{|c|}{ Post-test } \\
\hline & & & Standard deviation & Average & Standard deviation \\
\hline \multirow[t]{2}{*}{ Depression } & Control group & 3 & 1.84 & 3.05 & 1.76 \\
\hline & Test group & 1.75 & 1.81 & 0.5 & 0.52 \\
\hline \multirow[t]{2}{*}{ Social function } & Control group & 6 & 2.22 & 6.11 & 2.13 \\
\hline & Test group & 5.5 & 2.87 & 3.25 & 2.09 \\
\hline \multirow[t]{2}{*}{ Anxiety } & Control group & 7.05 & 2.66 & 7.27 & 2.82 \\
\hline & Test group & 3.66 & 2.96 & 1.5 & 2.79 \\
\hline \multirow[t]{2}{*}{ Physical function } & Control group & 8.27 & 2.88 & 8.27 & 3.02 \\
\hline & Test group & 5.75 & 2.83 & 3.41 & 2.10 \\
\hline \multirow[t]{2}{*}{ General health } & Control group & 24.33 & 7.53 & 24.72 & 7.32 \\
\hline & Test group & 16.66 & 5.75 & 8.66 & 3.31 \\
\hline \multirow[t]{2}{*}{ Environmental health } & Control group & 21.61 & 3.38 & 22.66 & 2.99 \\
\hline & Test group & 23.25 & 4.30 & 22.33 & 4.14 \\
\hline \multirow[t]{2}{*}{ Social health } & Control group & 8.77 & 2.55 & 10.5 & 3.79 \\
\hline & Test group & 9.08 & 4.92 & 5.91 & 1.72 \\
\hline \multirow[t]{2}{*}{ Physical health } & Control group & 19.27 & 5.57 & 18.72 & 5.26 \\
\hline & Test group & 18.58 & 4.03 & 14.25 & 3.72 \\
\hline \multirow[t]{2}{*}{ Psychological health } & Control group & 16.88 & 4.50 & 17 & 4.37 \\
\hline & Test group & 16.83 & 2.88 & 14.91 & 3.60 \\
\hline \multirow[t]{2}{*}{ Quality of life } & Control group & 66.55 & 13.84 & 68.88 & 12.05 \\
\hline & Test group & 67.75 & 12.36 & 57.41 & 9.90 \\
\hline
\end{tabular}

Table 3. The results of one-way variance analysis in Manva text on variables

\begin{tabular}{llccccc}
\hline Source & $\begin{array}{l}\text { Dependent } \\
\text { Variable }\end{array}$ & $\begin{array}{c}\text { Total } \\
\text { squares }\end{array}$ & $\begin{array}{c}\text { Freedom } \\
\text { degree }\end{array}$ & $\begin{array}{c}\text { Average } \\
\text { squares }\end{array}$ & F & $\begin{array}{c}\text { Meaning } \\
\text { fulness level }\end{array}$ \\
\hline The effect of & Depression & 8.701 & 1 & 8.701 & 7.137 & 0.015 \\
group & Social function & 25.433 & 1 & 25.433 & 14.223 & 0.001 \\
& Anxiety & 44.904 & 1 & 44.904 & 18.690 & 0.001 \\
& Physical function & 31.559 & 1 & 31.559 & 14.219 & 0.001 \\
& Social health & 75.571 & 1 & 75.571 & 8.130 & 0.001 \\
& Psychological health & 7.797 & 1 & 7.797 & 1.455 & 0.242 \\
& Physical health & 82.972 & 1 & 82.972 & 19.965 & 0.001 \\
& Environmental health & 0.852 & 1 & 0.852 & 0.095 & 0.761 \\
& Total score of mental health & 412.562 & 1 & 412.562 & 42.887 & 0.001 \\
& Total score of quality of life & 463.002 & 1 & 463.002 & 16.788 & 0.001 \\
\hline
\end{tabular}

According to the contents of table 3, it is observed that the measure of F related to mental health is equal to: $F=42.887$, $(\mathrm{P}<0.001)$ and the components of mental health namely: depression $\mathrm{F}=7.137,(\mathrm{P}<0.015)$, social function $\mathrm{F}=14.223$, Anxiety $\mathrm{F}=18.690$, physical function $\mathrm{F}=14.219$, $(\mathrm{P}<0.001)$ and they are meaningful. Also as it is observed in table 3 , the measure of $\mathrm{F}$ related to the variable of quality of life is equal to $\mathrm{F}=16.788$, social health $\mathrm{F}=8.130$, Physical health $\mathrm{F}=19.965,(\mathrm{P}<0.001)$ and they are meaningful, but the measures of $\mathrm{F}$ related to Psychological health, $\mathrm{F}=1.455$ $(\mathrm{P}<0.242)$ and environmental health $\mathrm{F}=0.095(\mathrm{P}<0.761)$ are not meaningful. According to this, it can be said that interference has been able to influence on quality of life and mental health of test groyup. 
This questionnaire has been translated and standardized in Iran by Nejat, Montazeri, Holakouie, Naeeni et al (2006).

\section{B-Goldberg mental Health Questionnaire GHQ}

General Health Questionnaire was manufactured in 1972 by Goldberg. This questionnaire includes 28 questions in four-degree Likert scale in four scales of physical symptoms, anxiety, disorder in social function and depression. Psychometric studies related to this questionnaire with 28 questions indicate significant validity and reliability. Goldberg and Blackwell (1970) by using of a check list of clinical interview on patients of surgery sector have mentioned the validity coefficient of this questionnaire, 0.80 (Hooman, 1998).

After data collection, the scores were analyzed after studying the assumptions related to covariance analysis method. Data were analyzed by spss-16 software.

\section{Methodology}

The sessions' protocol of acceptance and commitment therapy was held in 8 sessions (each session 90 minutes) in 4 successive weeks and the summary of each session's content has been presented in table 1.

\section{Findings}

Table 2 shows the descriptive components of research variables by separating the control and test groups.

For detecting the meaningfulness of difference between the above variables, covariance analysis was used.

According to the contents of table 3 , it is observed that the measure of $\mathrm{F}$ related to mental health is equal to: $\mathrm{F}=42.887,(\mathrm{P}<0.001)$ and the components of mental health namely: depression $\mathrm{F}=7.137,(\mathrm{P}<0.015)$, social function $\mathrm{F}=14.223$, Anxiety $\mathrm{F}=18.690$, physical function $\mathrm{F}=14.219$, $(\mathrm{P}<0.001)$ and they are meaningful. Also as it is observed in table 3 , the measure of $\mathrm{F}$ related to the variable of quality of life is equal to $\mathrm{F}=16.788$, social health $F=8.130$, Physical health $F=19.965$, $(\mathrm{P}<0.001)$ and they are meaningful, but the measures of $\mathrm{F}$ related to Psychological health, $\mathrm{F}=1.455(\mathrm{P}<0.242)$ and environmental health $\mathrm{F}=0.095(\mathrm{P}<0.761)$ are not meaningful. According to this, it can be said that interference has been able to influence on quality of life and mental health of test groyup.

\section{DISCUSSION}

In this study after that the subjects of test group were interfered, the general results indicate the effectiveness of group psychotherapy based on acceptance and commitment on mental health and quality of women's life with breast cancer of Urmia city. The obtained results of this study showed that group psychotherapy based on acceptance and commitment has been able to influence on all aspects of mental health in test group that the measure of independent variable in anxiety was more than three subscales of depression, social function, physical function.

Also, in this study psychotherapy based on acceptance and commitment was effective on two components of social and physical health and quality of life but interference hasn't been able to influence on two other components of quality of life namely psychological health and environmental health.

In a research that Mojtabaee and Gholamhosseini (2014) did on women with breast cancer and depression symptoms, concluded that Acceptance and Commitment Therapy is effective on decreasing depression symptoms in patients with breast cancer. The obtained findings of Acceptance and Commitment Therapy in the study of Mohabbat-Bahar, Malek-Rizi, Akbari and Moradi-Jou (2015) indicate meaningful decreasing in anxiety and depression symptoms of women with breast cancer.

The results of many studies of researchers prove that Acceptance and Commitment Therapy is effective in curing the anxiety and promotion of mental health (Veehof, Oskam, Schreus\&Bohlmijer, 2011; Arch, Eifert, Davies, Vilardaga, Rose \&Craske, 2012; Schoendorff, Parcell-Lalonde O. Connor, 2012; Fledderus, Bohlmeijer, Smit, Westerhof, 2010; Pull, 2009). Feros, Lane, Ciarrochi\&Blackledge (2013) who have applied the method of Acceptance and Commitment Therapy, concluded that Acceptance and Commitment Therapy can create changes in psychological flexibility, quality of life, distress and moods of participants in this test.

Various studies have concluded that Acceptance and Commitment Therapy is effective on improvement of depression from low to middle (Gaudiano, Nowlan, Brown, Epstein-Lubow\& 
Miller, 2013), obsessive-compulsive disorder (Towhig, Hayes,

Plumb, Pruitt et al, 2010), psychosis (Shawyer, Farhall, Mackinnon, Trawer et al, 2012), smoking (Gifford, Kohlenberg, Hayes, Pierson et al, 2011), tinnitus (Westin, Schulin, Hesser, Karlsson et al, 2011), epilepsy and emotional eating after gastric banding surgery (Weineland, Aryidsson, Kakoulidis, Dahl, 2012). Also this therapeutic method has been effective on nonclinical disorders like stress of work environment (Flaxman \& Bond, 2010), mental health (Masuda, Hayes, Fletcher, Seignourel et al, 2007) and weight loss (Lillis, Hayes, Bounting, Masuda).

The target of Acceptance and Commitment Therapy is to create the psychological flexibility namely creating the ability of selecting the action among different choices that is more proportionate, not an action which is done just for avoiding from thoughts, sensations, memories or distressful willingness or in fact it is imposed on the person and by using of such techniques and metaphors they struggle to help the persons by applying the method of without avoidance from annoying thoughts and sensations instead of reasoning (Hayes, Luma, Bond, Masuda, Lillis, 2006),therefore it can be expressed that the method of Acceptance and Commitment therapy can decrease the symptoms of anxiety, depression, disordered physical and social function and help them in order to improve the quality of life. Among the research limitations, cultural and ethnic differences of participants in this research can be mentioned, also with regard to the statistical population and limitation of sample that includes just the patients of Omid hospital in Urmia, therefore the selective sample can't be the representative of all patients of the country and its results can be generalized to other cities with caution.

Because one of the multiplier factors of life quality of patient with cancer is social support (Lehto, Ojanen, Kellokumpu-Lehtinen, 2005), therefore it is suggested the necessary trainings for accepting the patient to be performed for the relatives and family members.

\section{REFERENCES}

1. Nejat, Saharnaz; Montazeri, Ali; HolakouieNaeeni, Kourosh; Mohammad,
Kazem and Majdzadeh, Seyed Reza. Standardization of Quality Of Life questionnaire of World Health Organization (WHOQOLBREF): translation psychometric of Iranian species. Magazine of Health College and Health Research Institution, 2006; 4: 1-12.

2. Hooman, Abbas, Standardization of General Health Questionnaire. Tehran: Tehran University Publications, 1998.

3. American Cancer Society., Cancer Facts and Figures. Atlanta, Ga: American Cancer Society 2015.

4. Angiola, J.E \& Bowen, A.M., Quality of Life in Advanced Cancer An Acceptance and Commitment Therapy View .The Counseling Psychologist; 2013 ; 41(2): 313-335.

5. Arch,J.J ., Eifert ,G.H ., Davies, C ., Vilardaga, J.C.P., Rose, R.D \&Craske, M.G., Randomized clinical trial of cognitive behavioral therapy (CBT) versus acceptance and commitment therapy (ACT) for mixed anxiety disorders. $J$ Consult ClinPsychol; 2012; 80(5):750-65.

6. Avis ,N.E.., Crawford ,S. \& Manuel ,J., Quality of life among younger women with breast cancer.J ClinOncol ; 2005 ; 23(15): 3322-30.

7. Barnett, G.C ., Shah , M ., Redman ,K ., Easton, D.F., Ponder, B.A \&Pharoah, P.D., Risk factors for the incidence of breast cancer: do they affect survival from the disease? . Journal of clinical oncology: official journal of the American Society of Clinical Oncology ; 2008 ; 26(20):3310-6.

8. Colby ,D.A. ,\& Shifren, K., . Optimism, mental health, and quality of life: a study among breast cancer patients.Psychol Health Med; 2013 ; 18(1):10-20.

9. Costanza, M.E \& Chen, W.Y., Epidemiology and risk factors for breast cancer. Up to Date ; 2011; 19(2).

10. Demark-Wahnefried,W., Aziz,N.M ., Rowland, J.H \& Pinto, B.M, Riding the crest of the teachable moment: promoting long-term health after the diagnosis of cancer. Journal of Clinical Oncology 2005; 23(24):5814-30.

11. Drageset, S. \& Lindstrøm , T. C., The mental health of women with suspected breast cancer: the relationship between social support, anxiety, coping and defence in maintaining mental health.J PsychiatrMent Health Nurs; 2003; 10(4):4019.

12. Esmaili ,R., Abed-Saiidi , J \&AlaviMajd ,H., A survey of the body image of mastectomies women referring to Imam Khomeini and Imam Hussein hospitals in Tehran, Iran. Indian Journal PsycholMedical ; 2010; 32(1): 34-7.

13. Feros, D.L ., Lane , L .,Ciarrochi , J. \& Blackledge, J. T., Acceptance and Commitment 
Therapy (ACT) for improving the lives of cancer patients: a preliminary study.Psycho-Oncology; 2013 ; 22(2):459-464.

14. Flaxman, P.E \& Bond, F.W., A randomized worksite comparison of acceptance and commitment therapy and stress inoculation training. Behaviour Research and Therapy; 2010; 48:816-20.

15. Fledderus, M ., Bohlmeijer ,E.T., Smit, F \& Westerhof, G.J., . Mental health promotion as a new goal in public mental health care : A randomized controlled trial of an intervention enhancing psychological flexibility. Am J Public Health; 2010; 100(12): 2372.

16. Gaudiano , B.A ., Nowlan , K ., Brown , L.A ., Epstein-Lubow , G \& Miller , I.W., An Open Trial of a New Acceptance-Based Behavioral Treatment for Major Depression with Psychotic Features. BehavModif; 2013; 37(3): 324-355.

17. Gifford ,E.V ., Kohlenberg, B.S ., Hayes, S.C ., Pierson, H.M ., Piasecki ,M.P., Antonuccio , D.O\&Palm, K.M., Does acceptance and relationship focused behavior therapy contribute to bupropion outcomes? A randomized controlled trial of functional analytic psychotherapy and acceptance and commitment therapy for smoking cessation. Behav Ther ; 2011; 42:700-15.

18. Hayes, S. C.., Luoma, J. B.., Bond, F. W.., Masuda, A. \& Lillis, J., . Acceptance and commitment therapy: model, processes and outcomes.Behavior Research Therapy ; 2006; 44(1): 1-25.

19. Hayes, S.C ., Strosahl, K.D \& Wilson, K.G., Acceptance and commitment therapy: The process and practice of mindful change (2nd edition). New York, NY : The Guilford Press, 2012.

20. Jemal, A ., Bray, F ., Center, M. M ., Ferlay, J ., Ward, E \& Forman, D., Global cancer statistics . CA: a cancer journal for clinicians; 2011; 61(2): 69-90.

21. Lehto, U.S .,Ojanen, M .,Dyba, T .,Aromaa, A. \&Kellokumpu-Lehtinen, P., Baseline psychosocial predictors of survival in localized breast cancer. British journal of cancer; 2006; 94(9):1245-52.

22. Lehto, U.S. , Ojanen, M. \&KellokumpuLehtinen, P., Predictors of quality of life in newly diagnosed melanoma and breast cancer patients .Ann Oncol 2005;16(5):805-16.

23. Lillis, J ., Hayes ,S.C ., Bunting ,K \& Masuda A., . Teaching acceptance and mindfulness to improve the lives of the obese: a preliminary test of a theoretical model. Ann BehavMed; 2009; 37:58-69.
24. Lundgren, T ., Dahl ,J ., Melin ,L \&Kies, B ., . Evaluation of acceptance and commitment therapy for drug refractory epilepsy: a randomized controlled trial in South Africa - a pilot study .Epilepsy ; 2006; 47:2173-9.

25. Masuda, A., Hayes, S.C ., Fletcher, L.B., Seignourel, P.J ., Bunting, K .,Herbst, S.A.,Twohig,M.P\& Lillis, J ., The impact of Acceptance and Commitment Therapy versus education on stigma toward people with psychological disorders. Behavior Research and Therapy;2007; 45(11) : 2764-2772.

26. Mohabbat-Bahar, S ., Maleki-Rizi, F., Akbari, M.E \& Moradi-Joo,M., Effectiveness of Group Training Based on Acceptance and Commitment Therapy on Anxiety and Depression of Women with Breast Cancer. Iran J Cancer Prev ; 2015; 8(2): 71-76.

27. Mojtabaie, M \&Gholamhosseini, S., Effectiveness of Acceptance and Commitment Therapy (ACT) to reduce the symptoms of anxiety in women with breast cancer. Journal of Social Issues \&Humanities; 2014; 4(2): 522-527.

28. Plumb,J.C., Stewart, I ., Dahl, J \& Lundgren, T In Search of Meaning: Values in Modern Clinical Behavior Analysis. The Behavior Analyst; 2009; 32(1): 85-103.

29. Pull ,C.B., Current empirical status of acceptance and commitment therapy. Curr Opin Psychiatry 2009; 22(1):55-60.

30. Reich, M ., Lesur, A \&Perdrizet-Chevallier, C., Depression, quality of life and breast cancer: a review of the literature. Breast Cancer Res Treat 2008; 110(1):9-17.

31. Reyes-Gibby,C.C., Anderson,K.O Morrow, P.K Shete, S \& Hassan, S., Depressive symptoms and health-related quality of life in breast cancer survivors. J Womens Health (Larchmt) ; 2012; 21(3): 311-8.

32. Schoendorff, B., Purcell-Lalonde ,M., O’Connor, K., Third Wave Therapies in the treatment of Obsessional Compulsive Disorder: Applying Acceptance and Commitment Therapy. Santementale au Quebec; 2012; 38(2):153-73.

33. Shawyer ,F ., Farhall ,J ., Mackinnon, A ., Trauer, T., Sims , E ., Ratcliff, K ., Larner, CH ., Thomas, N., Castle, D., Mullen, P \& Copolov, D., A randomized controlled trial of acceptance-based cognitive behavioral therapy for command hallucinations in psychotic disorders .Behaviour Research and Therapy2012; 50:110-21.

34. Skevington, S. M ., Lotfy, M \& O’Connell, K. A., The World Health Organization's WHOQOL-BREF quality of life assessment: psychometric properties and results of the international field trial. A report from the 
WHOQOL group .Quality of life Research;2004; 13(2): 299-310.

35. So, W.K ., Marsh, G ., Ling, W.M ., Leung, F. Y., Lo, J.C ., Yeung, M \& Li, G.K., The symptom cluster of fatigue, pain, anxiety, and depression and the effect on the quality of life of women receiving treatment for breast cancer: a multicenter study. In Oncology nursing forum; 2009; 36(4) : E205- E214.

36. Spiegel, D., \& Riba, M. B., Managing Anxiety and Depression During Treatment. The breast journal; 2015; 21(1) : 97-103.

37. The World health report., Mental health . New understanding, new hope, 2001 .

38. Twohig,M.P ., Hayes, S.C ., Plumb, J.C ., Pruitt, L.D., Collins, A.B., Hazlett-Stevens, H \&Woidneck, M. R., A randomized clinical trial of acceptance and commitment therapy versus progressive relaxation training for obsessivecompulsive disorder. J Consult ClinPsych ; 2010; 78: 705-716.

39. Yankaskas ,B.C., Epidemiology of breast cancer in young women. Breast Dis ;2005 ; 23:3-8.

40. Yen .J.Y., Ko .C.H., Yen. C.F., Yang .M.J., Wu.
C.Y., Juan.C.H.,\&Hou . M.F ., Quality of life, depression, and stress in breast cancer women outpatients receiving active therapy in Taiwan. Psychiatry Clin Neurosci 2006; 60:147-53.

41. Veehof, M.M., Oskam, M.J., Schreurs, K.M \& Bohlmeijer, E.T., Acceptance-based interventions for the treatment of chronic pain: a systematic review and meta-analysis. Pain; 2011; 152(3): 533-42.

42. Weineland, S., Arvidsson, D., Kakoulidis ,T \& Dahl, J., Acceptance and commitment therapy for bariatric surgery patients, a pilot RCT. Obes Res Clin Pract; 2012; 6:e21-30.

43. Westin, V.Z., Schulin, M., Hesser, H., Karlsson ,M., Noe, R.Z., Olofsson, U., Stalby , M., Wisung, G., \& Andersson G., Acceptance and commitment therapy $\mathrm{v}$ tinnitus retraining therapy in the treatment of tinnitus: a randomized controlled trial. Behavior Research and Therapy; 2011; 49:737-47.

44. WHO Quality of Life Group., WHOQOLBREF Introduction, Administration and scoring, Field Trial version. World Health Organization, Geneva, 1996. 